\title{
A Multi-Reservoir Study of the Impact of Uncertainty in Pool Evaporation Estimates on Water-Availability Models
}

\author{
R. C. Phillips ${ }^{1,2}$, N. B. Kaye ${ }^{3}$, and J. R. Saylor ${ }^{4}$
}

AUTHORS: ${ }^{1}$ Davis \& Floyd, Inc., North Charleston, SC, USA. ${ }^{2}$ Department of Civil and Environmental Engineering, University of South Carolina, Columbia, SC, USA. ${ }^{3}$ Department of Civil Engineering, Clemson University, Clemson, SC, USA, nbkaye@clemson.edu. ${ }^{4}$ Department of Mechanical Engineering, Clemson University, Clemson, SC, USA.

KEYWORDS: evaporation; water resources; modeling; reservoir management

\begin{abstract}
Quantifying evaporative loss from reservoirs plays a critical role in sound water-availability management plans and in reservoir management. Various methods are used to quantify reservoir evaporation; however, each method carries a degree of uncertainty that propagates to model predictions of available water within a reservoir or a reservoir network. Herein, we explore the impact of uncertainty in reservoir evaporation on model outputs of historical and future water availability throughout the five major reservoirs in the Savannah River Basin in South Carolina, USA, using four different evaporation methods. Variability in the total available water is evaluated using the United States Army Corps of Engineers (USACE) 2006 Drought Contingency Plan hydrologic model of the Savannah River Basin, which incorporates recent water-management plans and reservoir controls. Results indicate that, during droughts, reservoir evaporation plays a large role in water-availability predictions, and uncertainty in evaporative losses produces significant uncertainty in modeled water availability for extreme events. For example, the return period for an event in which the availability of water in Lake Hartwell was reduced to $50 \%$ of full pool capacity varied from 38.2 years to 53.4 years, depending on the choice of evaporation parameterization. This is a variation of $40 \%$ in the return period, depending on the choice of evaporation method.
\end{abstract}

\section{INTRODUCTION}

Drought conditions and fluctuating reservoir levels have been persistent within the Savannah River Basin (SRB). For example, the 2006 to 2009 southeastern drought marked the most devastating historical drought period for this basin. Reservoir- and drought-management plans were revised and placed into immediate effect by the United States Army Corps of Engineers (USACE) to conserve the basin's water supply throughout this period. Even with such strategic management, the basin fell to less than $25 \%$ of its conservation storage by December of 2008, and Lake Hartwell and Lake Russell experienced their lowest observed pool elevations in history (USACE 2012).

The SRB reservoir network is placed under severe hydrologic stress during drought periods. Decreases in precipitation lower observed streamflow and increase restrictions on daily discharges from many of the reservoirs. Despite these restrictions, drought periods ultimately lower reservoir elevations. As water levels fall below normal pool conditions, less water is available for drinking water, agriculture, industrial applications, and hydropower generation. Furthermore, during periods of drought, water withdrawals tend to rise due to increased irrigation for agricultural and turf applications. Therefore, strategic management and drought plans are paramount for the economic well-being and survival of the inhabitants of the SRB. A strong understanding of the hydrologic cycle and its components is key to developing such plans.

Current models used to simulate the SRB hydrologic cycle rely on historically observed monthly pan evaporation estimates derived from registered National Weather Service (NWS) Class A evaporation pans and reservoir-specific pan coefficients derived from National Oceanic and Atmospheric Administration (NOAA) free-water surface evaporation grid data. Using these data, reservoir evaporative loss is predicted for the SRB and the total water availability is evaluated. However, estimates of reservoir evaporation derived from evaporation pans will introduce error in these models due to the low temporal resolution of pan observations, as well as the thermal and climatic differences between the pan and reservoir environments. 


\section{A Multi-Reservoir Study of the Impact of Uncertainty in Pool Evaporation Estimates}

During periods of high flow and precipitation, evaporation represents a fairly small fraction of the water available in the SRB. However, during drought and lowflow periods, reservoir evaporation represents a much larger fraction of available water. As a result, inaccuracies associated with reservoir evaporation estimates are magnified during times when models of water availability are needed most. Furthermore, if population and industry growth continues, along with more frequent and severe droughts, South Carolina and Georgia water use will continue to increase and cause evaporation to represent ever-larger portions of water available in the SRB. Therefore, a thorough understanding of the effect of uncertainty in reservoir evaporation on water-availability models is essential to the safe and proper management, operation, and allocation of the SRB's water supply. There have been prior studies looking at differences between evaporation predictions for different models (e.g., Sartori 2001; Rosenberry et al. 2007). However, to the authors' knowledge, no longitudinal study has been conducted that examines the propagation of uncertainty in evaporation into water-availability predictions for a network of reservoirs.

The primary objective of this research was to explore the impact of uncertainty in reservoir evaporation on predictions of reservoir water availability. Three mass transfer methods of estimating reservoir evaporation were used in conjunction with satellite remotely sensed reservoir surface temperatures to obtain daily evaporation estimates within the SRB. These evaporation data, along with measured pan evaporation data, were then used as inputs into the USACE SRB hydrologic model to assess differences in predicted water availability caused by differences in the evaporation estimation methods. Evaluating uncertainty in water-availability predictions requires the definition of total available water. In the case of municipal, industrial, and thermal power applications, available water is that which lies above the critical intake elevation for each reservoir, and this is used as the definition of available water hereinafter:

$$
\delta_{C}=\forall_{\text {min }}-\forall_{\text {critical }}
$$

where $\forall_{\min }$ is the simulated annual-minimum reservoir storage volume in cubic meters that occurs at the annual minimum water surface elevatiown $\left(Z_{\min }\right.$ in meters) and $\forall_{\text {critical }}$ the reservoir storage volume in cubic meters at the critical intake elevation (in meters). A physical representation of Equation 1 is presented in Figure 1. Throughout this paper, $\delta_{C}$ is used as a proxy for the amount of available water within each reservoir, while differences in observed $\delta_{C}$ are used as a proxy for the uncertainty in water-availability predictions.

The goal of this study was to evaluate the impact of uncertainty in evaporation estimates on the uncertainty in predicted water availability. However, the objective of the availability analysis was not to evaluate whether any one method of estimating reservoir evaporation was more accurate than the other, but to assess the uncertainty in wateravailability predictions with respect to varying evaporation parameterizations, using the pan method as a baseline. Water availability was computed using HEC-ResSim, a reservoir network software developed and used by the USACE Hydrologic Engineering Center. The two key inputs to the model in this study were daily evaporation and unimpaired flow. The model was run for four different evaporation estimation methods. The four methods for estimating evaporation, their use in calculating unimpaired flows, and the resulting hydrologic model are described below.

\section{SITE DESCRIPTION}

The Savannah River Basin (SRB) originates in the Blue Ridge Mountains of Georgia, North Carolina, and South Carolina. The Savannah River forms most of the GeorgiaSouth Carolina border and stretches more than 300 miles to the Atlantic Ocean (GA EPD 2000). The upper Savannah River is governed by the United States Army Corps of Engineers (USACE), which operates three multipurpose reservoirs: (1) Lake Hartwell, which was completed in 1962; (2) Lake Russell (Richard B. Russell), which was completed in 1985; and (3) Lake Thurmond (J. Strom Thurmond), which was completed in 1954. Additionally, Duke Power's KeoweeToxaway Project, located above Lake Hartwell, is composed of three separate reservoirs: (1) Bad Creek Reservoir, which was completed in 1991; (2) Lake Jocassee, which was completed in 1973; and (3) Lake Keowee, which was completed in 1971.

A map of the basin and its main reservoirs is presented in Figure 2, while the major SRB reservoir geometric data is provided in Table 1. The river basin has a total drainage area of approximately $27,400 \mathrm{~km}^{2}$, of which approximately 11,900 $\mathrm{km}^{2}$ are in South Carolina, $15,100 \mathrm{~km}^{2}$ are in Georgia, and $453 \mathrm{~km}^{2}$ are in North Carolina (US-EPA 1999). The basin serves a total 2010 population of approximately 778,000 in South Carolina, 1.35 million in Georgia, and 3,950 in North Carolina. Along the SRB, there are 9 hydroelectric powergenerating facilities that deliver more than 3,300 megawatts for industrial and residential purposes.

\section{EVAPORATION METHODS}

\section{METHODS}

Four estimates of evaporation were used in this study, namely pan evaporation and three mass transfer methods. The pan evaporation data was taken from the Clemson University Class A pan located in Clemson, South Carolina, USA. The mass transfer methods take on a single general form:

$$
\dot{m}^{\prime \prime}=h_{m}\left(q_{s}^{*}-q_{a, r}\right)
$$

where $\dot{m}^{\prime \prime}$ is the mass transfer rate in $\mathrm{kgm}^{-2} \mathrm{~s}^{-1}, h_{m}$ is the general evaporative mass transfer coefficient with the same 
Phillips, Kaye, Saylor

Table 1. SRB major reservoir geometry information.

\begin{tabular}{|c|c|c|c|c|c|}
\hline Reservoir & $\begin{array}{c}\text { Surface } \\
\text { Area }^{1,2}\left(\mathrm{~km}^{2}\right)\end{array}$ & $\begin{array}{c}\text { Mean } \\
\operatorname{Depth}^{2}(\mathbf{m})\end{array}$ & $\begin{array}{c}\text { Max } \\
\operatorname{Depth}^{2}(\mathbf{m})\end{array}$ & $\begin{array}{c}\text { Shoreline } \\
\text { Length }^{3}(\mathrm{~km})\end{array}$ & Volume $\left(\mathrm{Mm}^{3}\right)$ \\
\hline Jocassee & 30.6 & 48.1 & 99.4 & 121 & 1,490 \\
\hline Keowee & 75.0 & 16.0 & 90.5 & 483 & 1,070 \\
\hline Hartwell & 227 & 14.0 & 53.6 & 1,550 & 3,130 \\
\hline Russell & 108 & 12.1 & 44.8 & 869 & 1,260 \\
\hline Thurmond & 283 & 11.3 & 43.3 & 1,930 & 3,070 \\
\hline
\end{tabular}

${ }^{1}$ Calculated at full pool elevation.

${ }^{2}$ Data supplied by SC Department of Health and Environmental Control.

${ }^{3}$ Data supplied by USACE.

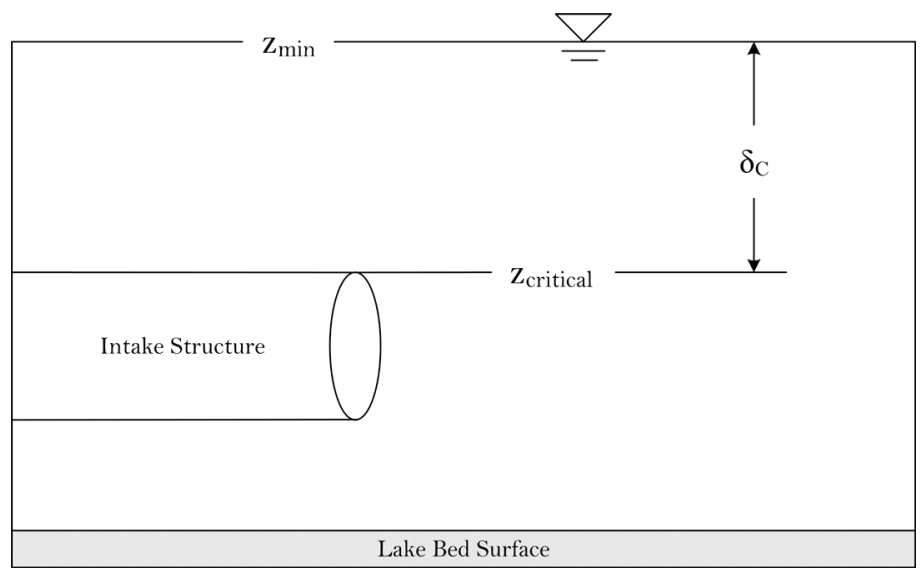

Figure 1. Physical representation of an individual reservoir's water availability, $\delta_{C}$, which is the volume of water above the intake invert.

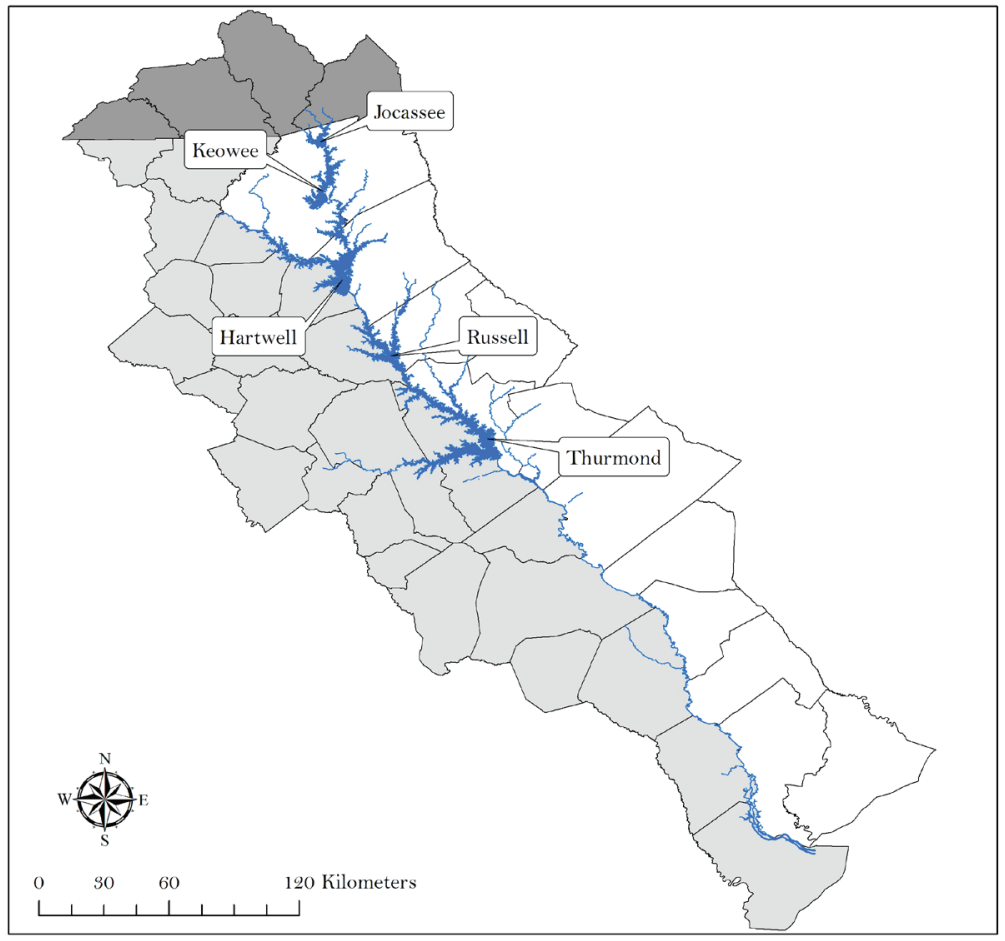

Figure 2. Major reservoirs of the SRB. North Carolina, South Carolina, and Georgia counties are represented as dark grey, white, and light grey, respectively. Data courtesy of the South Carolina Department of Natural Resources (SCDNR) and the United States Census Bureau. 


\section{A Multi-Reservoir Study of the Impact of Uncertainty in Pool Evaporation Estimates}

units as $\dot{m}^{\prime \prime}$, is the saturated specific humidity of water vapor at the temperature of the water surface, and $q_{a, r}$ is the specific humidity of $q_{s}^{*}$ ter vapor at the ambient air temperature at some reference height (both in $\mathrm{kg} / \mathrm{kg}$ ). Each of the three methods differ in the mass transfer coefficient, $h_{m}$, which are derived from various theoretical and experimental approaches. The evaporation mass transfer rate presented in Equation 2 can be converted to an hourly evaporation rate as: where $E V$ is the evaporation rate in $m m h^{-1}$ and $\rho_{w}$ is the density of water.

$$
E V=\frac{\dot{m}^{\prime \prime}}{\rho_{w}} \cdot \frac{60 \mathrm{sec}}{1 \text { hour }}
$$

While there are a multitude of mass transfer models available for $h_{m}$, three distinct examples were used in this research: the turbulent boundary layer (TBL), general aerodynamic (AERO), and heat transfer (HT) models (Brutsaert 1982; Ham 1999; Sartori 2000; Gupta 2001). The expressions for $h_{m}$ for each model are:

$$
h_{m}=\left\{\begin{array}{lc}
\frac{\rho_{a} \bar{u}_{r} C d_{r}^{\frac{1}{2}}}{13.6 S c^{\frac{2}{3}}-13.6+C d_{r}^{-\frac{1}{2}}} & \text { for TBL } \\
\rho_{a} \bar{u}_{r} C_{e} & \text { for AERO } \\
\frac{0.622 C_{1}\left(0.025+0.36 C_{2} \bar{u}_{r}\right)}{h_{w} P_{a}} & \text { for HT }
\end{array}\right.
$$

Here, ambient air density is denoted by $\rho_{a}\left(\mathrm{kgm}^{-3}\right), \bar{u}_{\mathrm{r}}$ is the mean wind speed $\left(m s^{-1}\right)$ at a given reference height, $C d_{r}$ is a surface drag coefficient, $S c$ is the Schmidt number (kinematic viscosity divided by the molecular diffusivity of water vapor), $C_{e}$ is the water-vapor transfer coefficient, $C_{1}$ and $C_{2}$ are wind speed coefficients, $h_{w}$ is the latent heat of vaporization of water $\left(\mathrm{Jkg}^{-1}\right)$, and $P_{a}$ is the atmospheric pressure (Pascals). It is important to note that the TBL method is nonlinear in wind speed due to $C d_{r}$, the AERO method is linear in wind speed, and the HT method is linear in wind speed with an additive term.

Applying these models to the SRB requires measurements of reservoir surface temperature $\left(T_{s}\right)$, ambient air temperature $\left(T_{a}\right)$, relative humidity $(\varphi)$, and average wind speed $\left(\bar{u}_{r}\right)$. See Phillips et al. (2016) for more details on obtaining $h_{m}$. Accurate methods must be used to estimate and measure each of these parameters when developing reliable evaporation estimates for the reservoirs in the SRB. Reservoir surface temperatures were obtained from the moderate-resolution imaging spectroradiometer (MODIS) sensor onboard the National Aeronautics and Space Administration (NASA) TERRA and AQUA satellites. This temperature data has a spatial resolution of approximately $1 \mathrm{~km}^{2}$, a temporal resolution of 4 overflights per day, and a temperature resolution of approximately $1 \mathrm{~K}$. All available data from July 2002 to December 2012 was used. Gaps in the data were filled using the Harmonic Analysis of Time
Series (HANTS) algorithm (Julien et al. 2006; Xu et al. 2013). Ambient air temperature, relative humidity, and mean wind speed were taken from archived Automated Surface Observing System (ASOS) data (Nadolski 1998). Hourly data sets were downloaded for the ASOS stations closest to each reservoir's centroid, namely ICAO:KCEU, ICAO:KAND, and ICAO:KAGS.

The hourly data sets were then used to calculate the ambient conditions $\left(T_{a}, \varphi, \bar{u}\right)$ for each satellite overpass time. See Phillips et al. (2016) for more details on the data collection and quality-assurance steps used in this study. The satellitebased Ts measurements and the ASOS ambient conditions data $\left(T_{a}, \varphi, \bar{u}\right)$ were then used in Equation 2, along with the three parameterizations for hm, to calculate four evaporation rates per day (i.e., one evaporation rate per satellite overpass) for each evaporation method over the period of record (July 2002 to December 2012). The individual sub-daily data sets were then averaged to produce three distinct daily and monthly time series of evaporation for each reservoir.

\section{UNIMPAIRED FLOWS}

Unimpaired flow is an estimate of the flow that would have occurred in a river basin in the absence of any human-made structures (e.g., dams) and anthropogenic water fluxes. The use of unimpaired flows by water-resource managers is a common practice in developing drought-contingency and water-management plans (Gleick 1987; Lettenmaier and Gan 1990; Tarboton 1995). The original unimpaired flow data set for the SRB implemented herein was developed by ARCADIS, U.S., Inc., as part of the Surface Water Availability Modeling and Technical Analysis for Statewide Water Management Plan that was prepared for the Georgia Department of Natural Resources (ARCADIS 2010). The unimpaired flow is defined as:

$$
U I F=L I F+N E T E V A P_{F}+N E T W U
$$

where UIF is the local unimpaired incremental flow $\left(m^{3} s^{-1}\right)$; LIF is the local incremental flow $\left(\mathrm{m}^{3} \mathrm{~s}^{-1}\right)$; NETWU is the net water consumption resulting from municipal, industrial, and agricultural uses, and from groundwater pumping $\left(\mathrm{m}^{3} \mathrm{~s}^{-1}\right)$; and NETEVAP $F$ is the flow due to reservoir net evaporation effects $\left(m^{3} s^{-1}\right)$ given by:

$$
\left.\operatorname{NETEVAP}_{F}=[(E V-P)) \cdot A+R O C \cdot P \cdot A\right]
$$

where $E V$ is the rate of surface evaporation $\left(m m h^{-1}\right), P$ is the rate of precipitation $\left(m m h^{-1}\right), \mathrm{A}$ is the reservoir surface area $\left(m^{2}\right)$, and $R O C$ is the sub-basin runoff coefficient (ARCADIS 2010). A complete and detailed description of the UIF computation process is beyond the scope of this work and can be obtained from ARCADIS (2010). All UIF, LIF, NETEVAP $F$, and NETWU data sets, as well as the 
precipitation time series, $P$, area time series, $A$, and runoff coefficient values, $R O C$, were obtained from the Georgia Environmental Protection Division (GA EPD).

\section{HEC-RESSIM MODEL}

The modeling environment used to simulate the SRB herein is HEC-ResSim, developed and used by the USACE Hydrologic Engineering Center. The HEC-ResSim model used by USACE incorporates physical reservoir data, such as net evaporation, net evaporation plus runoff, and stagestorage relationships, as well as stream routing steps, dam flow properties, diverted outlets, and power-plant operations for each of the five major SRB reservoirs, including Bad Creek Reservoir. Although each of these components play an intricate part of the model, the key lies within the operational rules embedded in the reservoir model.

The model used for this research contains the operational rules and data sets for the 2006 Drought-Contingency Plan (2006-DCP), as well as the water-management plan during this period, collectively referred to as the 2006-DCP model hereinafter. Within the 2006-DCP model, Lake Jocassee, Lake Keowee, and Bad Creek operate under the storage-balance rule set imposed by Duke Energy, requiring safe operating levels for the Oconee County Nuclear Plant. Lake Hartwell, Lake Russell, and Lake Thurmond operate under the 2006DCP developed by USACE. Ultimately there are three fundamental inputs that govern the result of the model: (1) UIF data sets, developed by ARCADIS (2010); (2) reservoir pool evaporation; and (3) human water consumption. It is important to note that the 2006-DCP model is not the current model used by USACE to manage water availability in the SRB. However, the 2006-DCP was the only reservoir model made available at the time of this research. The 2006-DCP model was obtained from the USACE Savannah District, located in Savannah, Georgia. See USACE (2006) for in-depth descriptions of the hydrologic and hydraulic components included in the 2006-DCP.

\section{BASIN HYDROLOGIC MODELING}

Differences in the parameterization of the four evaporation methods (i.e., pan evaporation and the three mass transfer methods) yield differences in estimates of reservoir evaporation along the SRB. These evaporation estimates play a significant role in modeling the hydrologic cycle, assessing water availability, and developing water-management and drought-contingency plans. As a result, a proper understanding of the effect of uncertainty in evaporation estimates on basin water-availability predictions is needed. Therefore, a method was applied to understand the response of the SRB reservoir network to the evaporation estimates described above and in Phillips et al. (2016).

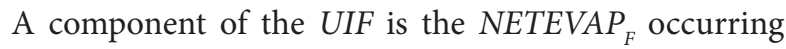
from each reservoir. The $N E T E V A P_{F}$ time series currently used by USACE were developed by ARCADIS (2010) using NOAA monthly evaporation observations, along with Hamon potential evapotranspiration (PET) estimates (Hamon 1960). Monthly evaporation observations were obtained from geospatial evaporation grids developed by the National Weather Service (NWS), which represents freewater surface evaporation for any location in the contiguous United States (Farnsworth and Thompson 1982). More details on development of the NETEVAP $F$ time series used by USACE is provided by ARCADIS (2010). Consequently, the current UIF is not representative of the TBL, AERO, HT, and pan evaporation estimates described above and in Phillips et al. (2016).

It is important to note that the pan evaporation estimates described in Phillips et al. (2016) and implemented herein were developed independent of those used by USACE. Evaporation based on the pan method used in this research was developed using monthly reservoir-specific pan evaporation coefficients and a long-term pan station located in Clemson, South Carolina. Monthly pan coefficients, $K_{p}$, were estimated (see Figure 3) for each reservoir using NWS free-water surface evaporation geospatial grids, $F W S_{\text {grid }}$ based on observed pan evaporation measurements in Clemson, South Carolina, $E_{p a n}$, as:

$$
K_{p}=\frac{F W S_{\text {grid }}}{E_{\text {pan }}} .
$$

Although the UIF data in the current 2006-DCP model is not representative of TBL, AERO, HT, and pan evaporation estimates, a UIF set independent of any one evaporation parameterization should be developed and used in the 2006-DCP model, mainly since the UIF is dependent upon the evaporation estimates used to develop NETEVAP ${ }_{F}$. Furthermore, the goal of this research was to understand the effect of uncertainty in evaporation estimates on the total water availability in the SRB. As a result, a single UIF data set

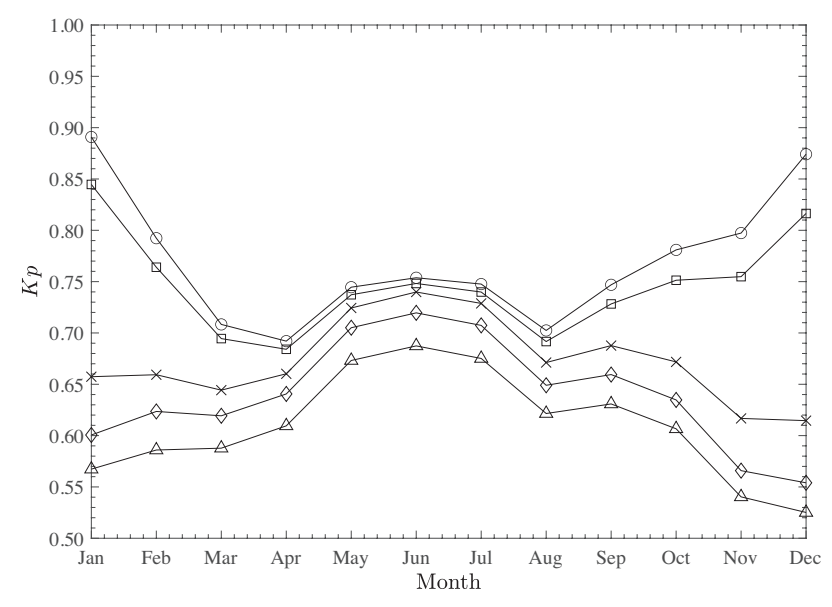

Figure 3. Monthly derived pan coefficients, $K_{p}$, for: Jocassee $(\triangle)$, Keowee $(\diamond)$, Hartwell $(\times)$, Russell ( $\square$ ), and Thurmond ( $($ ) (used with permission from Phillips et al. 2016). 


\section{A Multi-Reservoir Study of the Impact of Uncertainty in Pool Evaporation Estimates}

for the basin was used as a baseline, while pool evaporation varied within the 2006-DCP model. Developing a UIF data set independent of any one of the four evaporation methods was achieved by first generating NETEVAP $P_{F}$ estimates for each of the evaporation methods. However, TBL, AERO, and HT evaporation estimates were not available until July 2002, and NETEVAP $F$ data sets for each of the reservoirs required evaporation estimates at reservoir completion. Although the TBL, AERO, and HT estimates were not available at reservoir completion, pan evaporation estimates were available starting in 1949, spanning the life of each reservoir. Therefore, an approach was applied to project the MODISderived evaporation estimates back to reservoir completion using pan-based evaporation estimates.

A series of adjustment factors was developed for each of the three mass transfer evaporation time series to project MODIS-derived reservoir evaporation estimates back to reservoir completion. First, monthly evaporation rates were computed for each of the four evaporation methods using the daily evaporation rates calculated using the pan data and mass transfer models. A time series of monthly adjustment factors was then developed for each of the SRB reservoirs from July 2002 to December 2012, given by:

$$
K_{M T}=\frac{1}{n} \sum_{i=1}^{n} \frac{E m_{M T}(i)}{E m_{p}(i)}
$$

where $K_{M T}$ is the monthly mass transfer evaporation adjustment factor, $E m_{M T}$ is the monthly evaporation total estimated by the mass transfer method (i.e., MODIS derived $T_{s}$ measurements), $E m_{p}$ is the monthly evaporation total estimated from the pan method, and $n$ is the total number of monthly ratios. Adjusted daily mass transfer estimates of reservoir evaporation were projected back to reservoir completion for each mass transfer method, given by:

$$
E d_{M T}=E d_{p} \cdot K_{M T}
$$

where $E d_{M T}$ is the adjusted daily mass transfer evaporation estimate and $E d_{p}$ is the original daily pan evaporation estimate. NETEVAP $P_{F}$ and UIF time series were then generated for each reservoir, as described in Equations 5 and 6, using the adjusted mass transfer evaporation estimates, pan evaporation estimates, $R O C$ data, reservoir precipitation data, $P$, and LIF data. This resulted in four UIF data sets for each of the five SRB reservoirs (i.e., TBL, AERO, HT, and pan). Finally, a single UIF data set for each reservoir was generated by taking the average of the individual UIF data sets.

\section{POOL EVAPORATION}

The surface area of each reservoir is calculated using the simulated reservoir level and area-stage relationships during a reservoir model run. Next, pool evaporation rates for the individual reservoirs are multiplied by the calculated surface area to obtain the pool evaporation flow, NETEVAP. These values are then subtracted from the UIF data sets to simulate the addition of the reservoirs within the basin. As a result of the development process of the UIF, the pool evaporation data used in the 2006-DCP model is represented as the net evaporation runoff rate, given by:

$$
N E T E V A P_{R}=E V-P+R O C \cdot P
$$

where NETEVAP $P_{R}$ is the net evaporation runoff rate.

The pool evaporation for each reservoir can be implemented as a constant monthly time series or a daily time series. Incorporating a daily time series within the model would generate more accurate results. However, since the SRB is modeled over the entire POR, "virtual" reservoirs are implemented prior to reservoir completion. Specifying a look-back elevation (i.e., the reservoir elevation the day prior to the simulation start date) constitutes the addition of each reservoir in the 2006-DCP model prior to the actual completion date. Since the reservoirs are "virtually" simulated prior to construction, the runoff flows that resulted from the land surface inundated by each reservoir must be subtracted out of the historically observed flows. The runoff flow concept is satisfied by $R O C$, as seen in Equation 10. However, a small problem still resides with the concept of the "virtual" reservoir.

Each reservoir is simulated and "added" into the SRB many years before the actual completion date. As a result, no surface temperature measurements exist for the reservoirs prior to completion. Moreover, pan evaporation estimates do not span the entire POR (1939-2008). Therefore, there is no way to predict reservoir evaporation using the aforementioned mass transfer method adjustments, as shown in Equation 9, and a daily time series of pool evaporation cannot be implemented. Consequently, a constant monthly pool evaporation time series was incorporated into the 2006DCP model for the entire simulated period, which is also currently done by USACE.

The first step in developing pool evaporation estimates for the 2006-DCP model was to identify POR years in which MODIS- and pan-derived evaporation estimates coexist. This time period was from July 2002 to December 2008. Next, daily reservoir NETEVAP ${ }_{R}$ time series were developed using the pan and mass transfer evaporation estimates. The daily NETEVAP ${ }_{R}$ time series were then summed to generate monthly NETEVAP $P_{R}$ values. Lastly, the monthly rates were averaged to produce the final monthly NETEVAP $P_{R}$ time series for each evaporation method and reservoir. It is important to note that monthly NETEVAP ${ }_{R}$ values were required for Bad Creek in the 2006-DCP model. The focus of this paper was on the major SRB reservoirs, and Bad Creek is negligibly small when compared to the other reservoirs. As a result, the 
monthly NETEVAPR values for Bad Creek were assumed to be equal to that of Lake Jocassee, due to the proximity of Bad Creek to Lake Jocassee.

\section{HISTORICAL RESERVOIR SIMULATIONS}

Historical simulations were run over the entire POR (January 1939 to December 2008) for each of the evaporation methods (i.e., pool evaporation estimates). This was done to encompass as many historical drought periods as possible. Each simulation was developed using the current 2006-DCP model and the computed NETEVAP ${ }_{R}$ monthly time series for each reservoir. However, daily net water-use data obtained from USACE, where available, were incorporated in the simulation, whereas USACE currently only incorporates constant monthly net water-use data at each diversion or constant daily discharge values. The start and end date selected for each simulation was January 2, 1939, and December 31, 2008, respectively, while the look-back date was set to January $1,1939$.

\section{FUTURE RESERVOIR SIMULATIONS}

The effect of future water use coupled with varying evaporation parameterizations was evaluated by implementing future daily projected water-use time series into the 2006-DCP model. Future water-use projections were obtained from an HDR Engineering, Inc., report (HDR 2013) that was developed as part of Duke Energy's KeoweeToxaway Hydroelectric Relicensing Project. Average-annual rates were computed in ten-year increments from 2016 to 2066 (HDR 2013) in which historical water-use data, where available, population growth predictions, developed by each state, power consumption per person data, and future plans of industry growth/decline were considered.

The average-annual net withdrawal rates developed by HDR (2013) provided some indication of future water use along the SRB. However, daily net water withdrawals needed to be generated for use in the 2006-DCP model. As a result, inter-year average-annual net withdrawal rates were interpolated using projections from HDR (2013) and an elliptical interpolation function. This provided continuous yearly average net withdrawal rates from 2010 to 2066. The projected withdrawal rates determined by HDR (2013) were average-annual rates and were assumed to be representative of each day within the calendar year. Consequently, daily projected water-use rates were developed based on the average-annual rates.

It was assumed that the future hydrologic setting would remain similar to that of the historical alternative. As a result, a greater focus is placed upon the effect of future water use only without changing the hydrology settings along the basin. Consequently, the same UIF data set was used for the future water-use projections as was used for the historical simulations. Since the historical UIF data set was used with the future water-use data, and water-use projections were only provided for 57 years, a set of corresponding historical dates was selected for running future simulations. The date range selected for the analysis was 1952 to 2008, which corresponds to projected years for 2010 to 2066 .

The future simulations incorporated the same operational and computational rules as the historical alternative. However, the UIF data implemented within the new alternative corresponded to the UIF time series from 1952 to 2008, not 1939 to 2008, with the inclusion of the projected daily water-use time series. Four simulations were developed and computed using the four monthly NETEVAP ${ }_{R}$ time series described in previous sections after development of the future alternative. The start and end date of each simulation was set to January 2, 1952, and December 31,2008 , respectively, while the look-back date was set to January 1, 1952. The future simulation represented the SRB behavior from January 2010 to December 2066. A summary table of data used and its source is given in Appendix A.

\section{RESULTS AND DISCUSSION}

The 2006-DCP model used in this paper allowed for the development of a continuous daily water-surface elevation time series for each of the major SRB reservoirs. Sample simulated Lake Hartwell daily water-surface elevations for the historical water-use alternative are presented in Figure 4. Lake Hartwell's daily simulated reservoir level showed a very clear pattern in the daily simulated water-surface elevation, under normal hydrologic conditions (i.e., non-drought periods). The daily reservoir elevation results were directly related to the operational data sets that make up the 2006DCP model. For example, during the fall, and under normal flow conditions, the virtual water manager, HEC-ResSim in this case, lowers Hartwell's reservoir elevation from $201 \mathrm{~m}$ to $200 \mathrm{~m}$ from October to January, while raising the reservoir elevation from $200 \mathrm{~m}$ to $201 \mathrm{~m}$ from January to April. These levels are maintained throughout normal flow conditions to account for heavy rainfall during the fall/winter and lighter rainfall during the summer. As a result, the pattern seen in Figure 4 was controlled by the operational and watermanagement plan built in the 2006-DCP model.

As discussed in the introduction, $\delta_{C}$ was used as a proxy for the amount of available water within each reservoir, while differences in the observed $\delta_{C}$ values were used as a proxy for the uncertainty in water-availability predictions. Hence, the critical intake reservoir elevations for the major SRB reservoirs are provided in Table 2.

\section{HISTORICAL WATER AVAILABILITY}

The annual-minimum storage volume above the critical intake elevation was computed for each of the SRB reservoirs and evaporation methods using the data provided in Table 
A Multi-Reservoir Study of the Impact of Uncertainty in Pool Evaporation Estimates

Table 2. Major SRB reservoir critical intake elevation summary (HDR 2013).

\begin{tabular}{|c|c|c|}
\hline Reservoir & $\begin{array}{c}\text { Critical Intake } \\
\text { Elevation (M AMSL) }\end{array}$ & Comments \\
\hline Jocassee & 329 & Hydropower operations limitation. \\
\hline Keowee & 240 & Oconee Nuclear Station limitation. \\
\hline Hartwell & 194 & $\begin{array}{l}\text { Clemson University Central Energy Facility intake. (Note: Although } \\
\text { Clemson University's Musser Fruit Farm irrigation intake is higher } \\
@ 197 \mathrm{~m} \text {, in the event this intake is exposed, the facility can purchase } \\
\text { water from the City of Seneca. Due to the alternate water source, the } \\
\text { Musser Fruit Farm intake @ EL } 197 \mathrm{~m} \text { is not considered as the critical } \\
\text { intake.) }\end{array}$ \\
\hline Russell & 143 & Hydropower operations limitation. \\
\hline Thurmond & 95 & $\begin{array}{l}\text { Columbia County Water Utility (GA) and McDuffie County-City of } \\
\text { Thomson (GA) raw water intake elevation (second-highest of three } \\
\text { intakes; if highest intake is exposed, the remaining two intakes are } \\
\text { capable of meeting water demands, thus making the second-highest } \\
\text { intake the critical intake elevation); hydropower operations limitation. }\end{array}$ \\
\hline
\end{tabular}

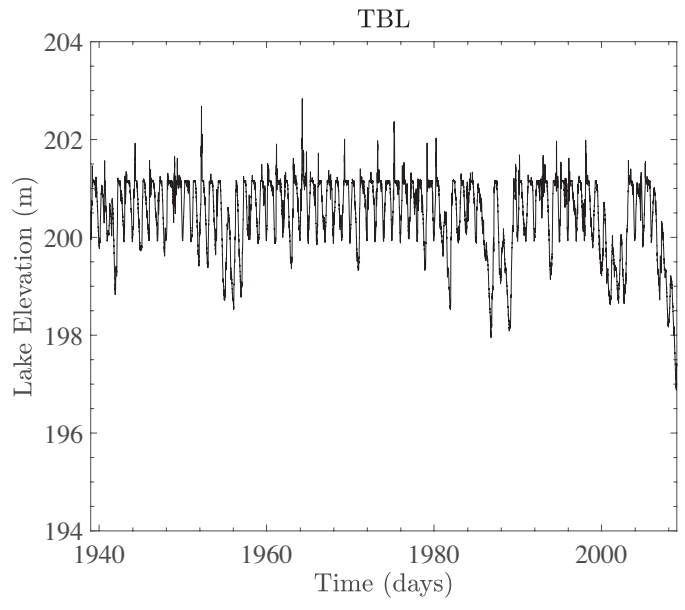

(a)

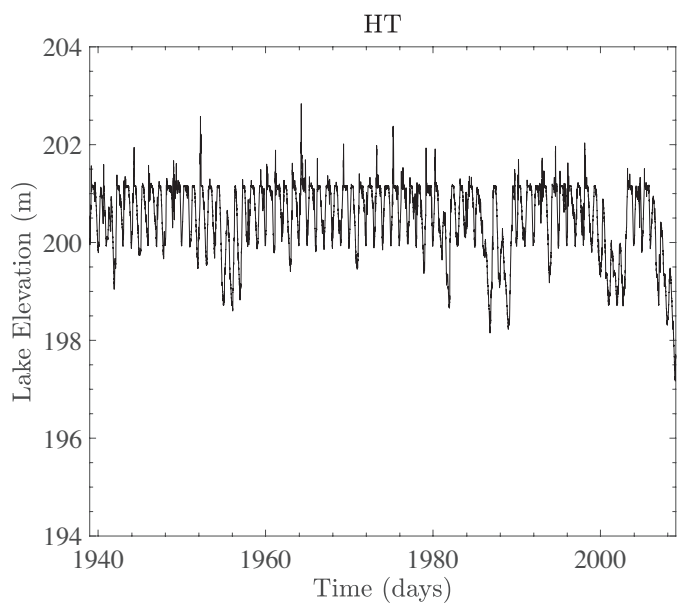

(c)

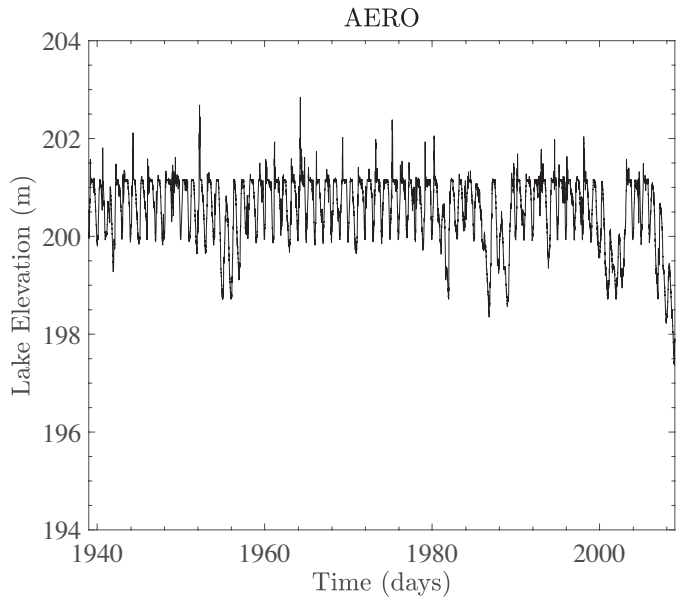

(b)

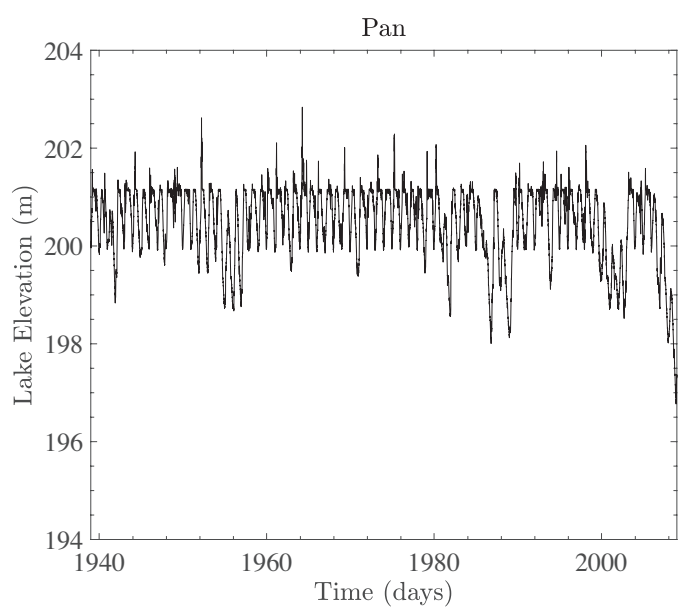

(d)

Figure 4. Lake Hartwell daily simulated reservoir elevation from 1939 to 2008: (a) TBL; (b) AERO; (c) HT; and (d) pan. 
2, the daily simulated reservoir elevation/storage data sets, and the reservoir stage-storage curves. The maximum, minimum, and average $\delta_{C}$ among the four evaporation methods presented herein were computed to illustrate this uncertainty in water-availability estimates due to evaporation parameterization. These results are plotted versus year in Figure 5 for each of the five major reservoirs in the SRB based on historical water consumption. In general, each of the reservoirs showed some degree of uncertainty in the predicted $\delta_{C}$.

The magnitude and degree of uncertainty in the predicted $\delta_{C}$ showed the effect of varying evaporation parameterizations on water-availability predictions. Notable drought occurrences during the SRB POR (1939-2008) were 1938-1944, 1950-1957, 1965-1970, 1976-1978, 19801982, 1985-1990, 1993, 1995, 1998-2003, and 2006-2009 (Barber and Stamey 2000; Douglass 2002; USACE 2012). Figure 5 shows that many of the periods when uncertainty was observed in the predicted $\delta_{C}$ correspond to these drought years. Under normal flow conditions, uncertainty is minimized due to the large amount of available water within the basin and reservoir levels being controlled by seasonal operational rules. However, under low flow conditions (i.e., drought periods), uncertainty in water-availability predictions, due to uncertainties in evaporation estimates, are magnified for many of the SRB reservoirs, as evaporation plays a relatively larger role in these periods.

Uncertainty during several of the drought periods represented a significant fraction of available water within the basin and warrants further investigation by waterresource managers to achieve efficient and effective reservoir management during such drought periods. For example, during 1988, Lake Jocassee, Lake Keowee, Lake Hartwell, Lake Russell, and Lake Thrumond experienced uncertainty in the simulated $\delta_{C}$ of $52.98 \times 106 \mathrm{~m}^{3}, 1.88 \times 106 \mathrm{~m}^{3}, 90.99 \times$ $106 \mathrm{~m}^{3}, 4.95 \times 106 \mathrm{~m}^{3}$, and $101.88 \times 106 \mathrm{~m}^{3}$, respectively. To put these numbers in context, according to water reports prepared by Greenville Water Systems, the city of Greenville, South Carolina (population of 60,379; US Census Bureau 2011), pulled an approximate daily average of $102,000 \mathrm{~m}^{3}$ from Lake Keowee during the 2012 fiscal year (Greenville Water Systems 2012). Hence, an uncertainty in $\delta_{C}$ of $1.88 \times$ $106 \mathrm{~m}^{3}$ represents the city of Greenville's daily water withdrawal from Lake Keowee for approximately 18 days.

As noted above, uncertainty in the predicted $\delta_{C}$ of each reservoir was more prevalent during drought periods. During drought periods, the net total inflow to each reservoir is limited. This net reduction in inflow triggers water managers (i.e., Duke Energy and USACE) to decrease the outflow of several reservoirs within the SRB to maintain an adequate water supply. Subsequently, many of the SRB reservoirs begin to experience lower reservoir elevations (i.e., smaller $\delta_{C}$ ). Under the above conditions, the net evaporative loss from each reservoir now begins to represent a larger fraction of the total available water within the basin, when compared to normal flow conditions. Consequently, the reservoir level and $\delta_{C}$ are more heavily influenced by the evaporation occurring over the reservoir surface. This observation was characterized by plotting the annual range of $\delta_{C}$ against the average annual $\delta_{C}$ and is presented in Figure 6. Here the range is given by:

$$
\Delta \delta_{C}=\delta_{C} \max -\delta_{C} \min
$$

and the average is given by:

$$
\overline{\delta_{C}}=\frac{1}{4} \sum_{i=1}^{n} \delta_{C}(i)
$$

where $\Delta \delta_{C}, \delta_{C} \max , \delta_{C} \min$, and $\overline{\delta_{C}}$ are the annual range, maximum, minimum, and average $\delta_{C}$, respectively, among the four evaporation methods.

Plots of $\Delta \delta_{C}$ versus are presented in Figure 6 to illustrate the increase in variability during periods of low flow. The figure shows a degree of scattering in the results. However, in general, as the reservoir pool elevation decreased from the full pool elevation, the observed uncertainty, $\Delta \delta_{C}$, increased. Lake Keowee was the only reservoir that did not exhibit this behavior. In contrast, Lakes Hartwell and Thurmond showed the largest range of results. This result is directly related to the average surface area of each of these reservoirs. Lakes Hartwell and Thurmond have the largest surface area of the reservoirs within the basin; therefore, the small uncertainty in the predicted water level due to evaporation translates to a much larger uncertainty in terms of the storage volume. Each of the reservoirs, except for Lake Russell, are lowered each year to a target minimum elevation, due to the absence or presence of rainfall. Lake Russell is kept at a nearly constant full-pool elevation of $145 \mathrm{~m}$, due to the critical intake at $143 \mathrm{~m}$. As a consequence of water-management and operational rules, $\delta_{C}$ values for Lakes Jocassee, Keowee, Hartwell, and Thurmond were never equal to the full pool volume.

\section{FUTURE WATER AVAILABILITY}

The above results correspond to the historical water-use alternative. The effect of industry and population growth on this uncertainty is now presented for each evaporation method. The distribution of $\delta_{C}$ for each reservoir and evaporation method was computed to demonstrate the change in availability due to increased water demand. This was done for both the historical and the future water-use scenarios. While the distribution of $\delta_{C}$ were being generated, only the last 57 years of data for each reservoir simulation scenario were used, corresponding to the years 1952-2008 and 20102066 for the historical and future scenarios, respectively. 
A Multi-Reservoir Study of the Impact of Uncertainty in Pool Evaporation Estimates

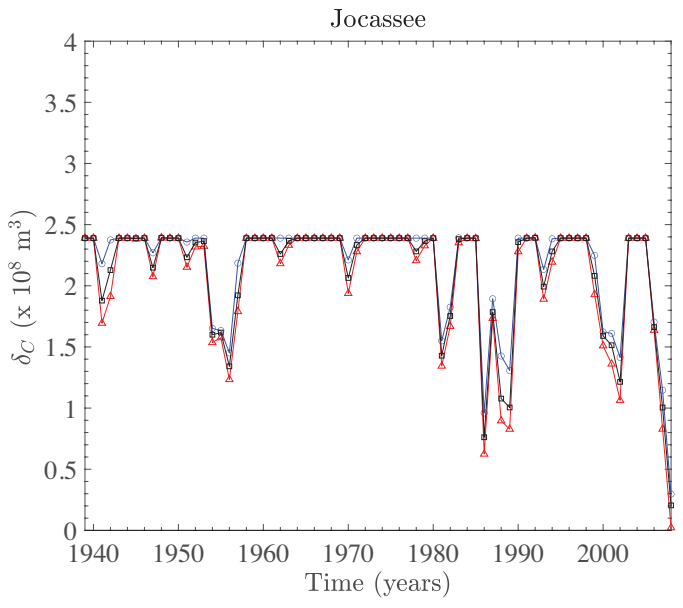

(a)

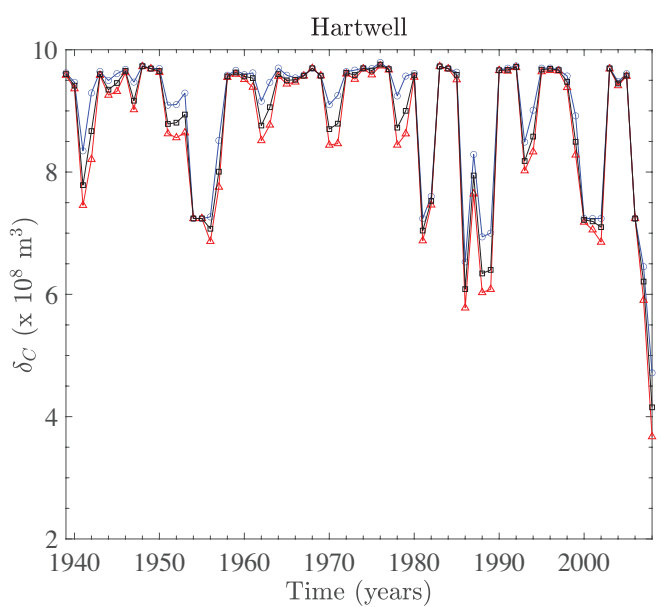

(c)

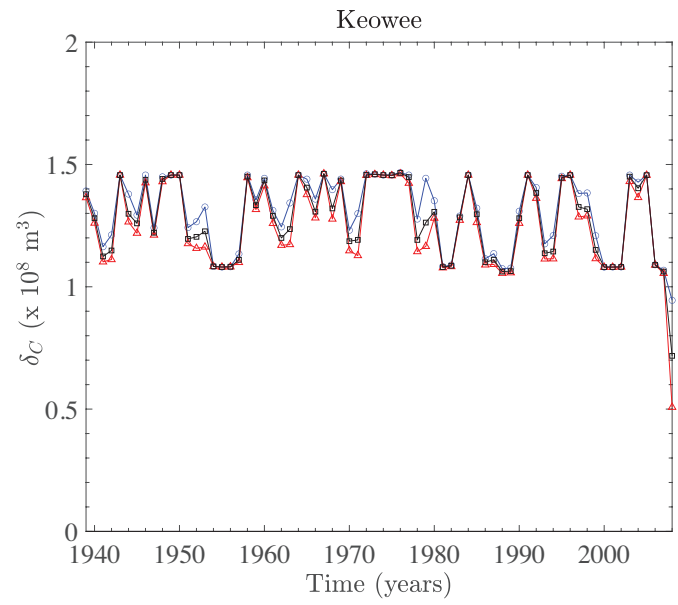

(b)

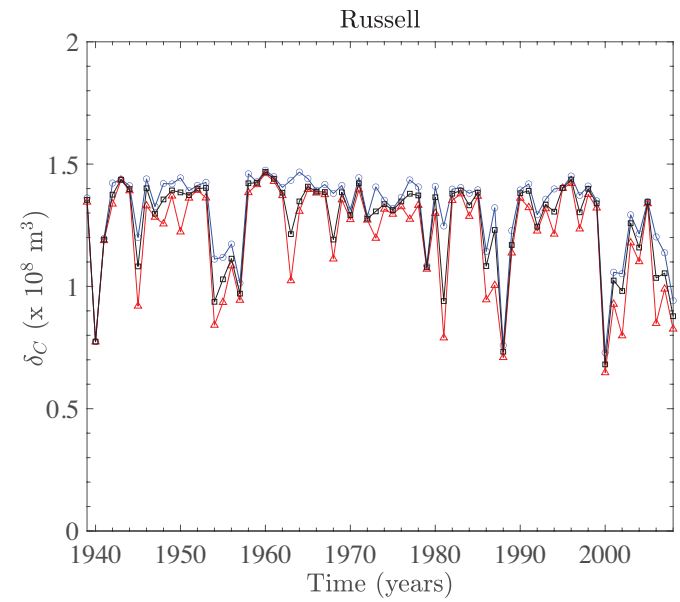

(d)

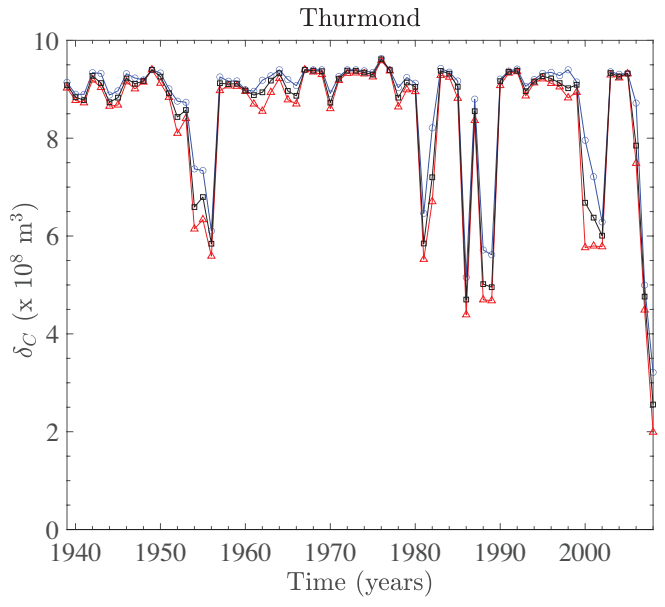

(e)

Figure 5. Historical simulated yearly maximum ( $\bigcirc$-blue), minimum ( $\triangle$-red), and average ( $\square$-black) volume of water above the critical intake $\left(\delta_{C}\right)$ from 1939 to 2008: (a) Jocassee; (b) Keowee; (c) Hartwell; (d) Russell; and (e) Thurmond. 


\section{Phillips, Kaye, Saylor}

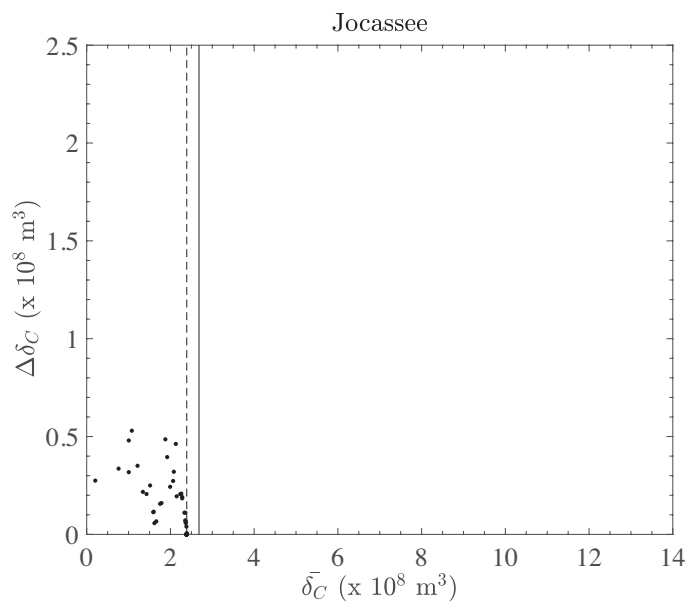

(a)

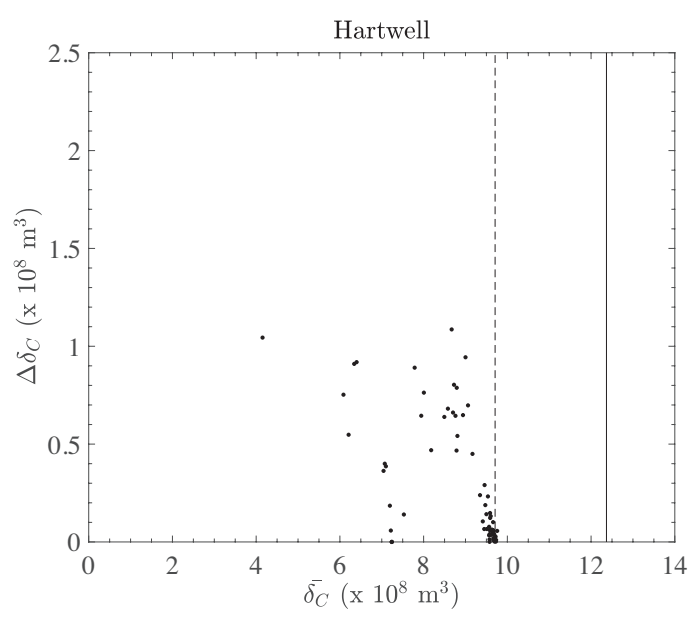

(c)

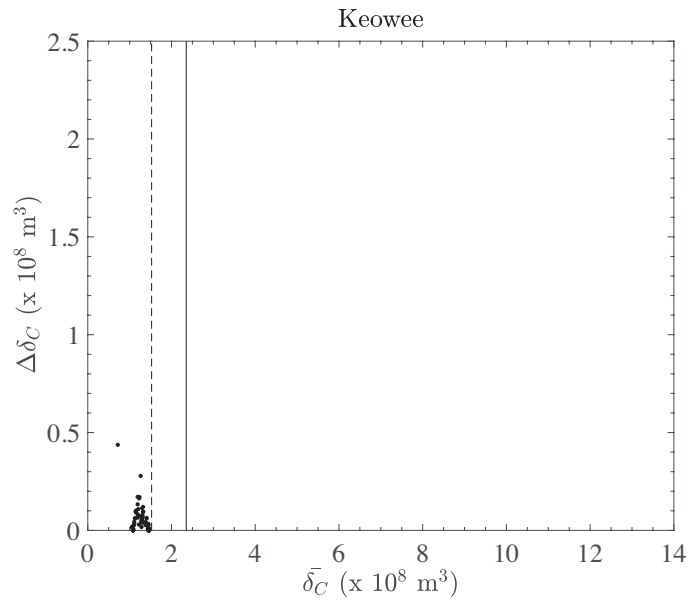

(b)

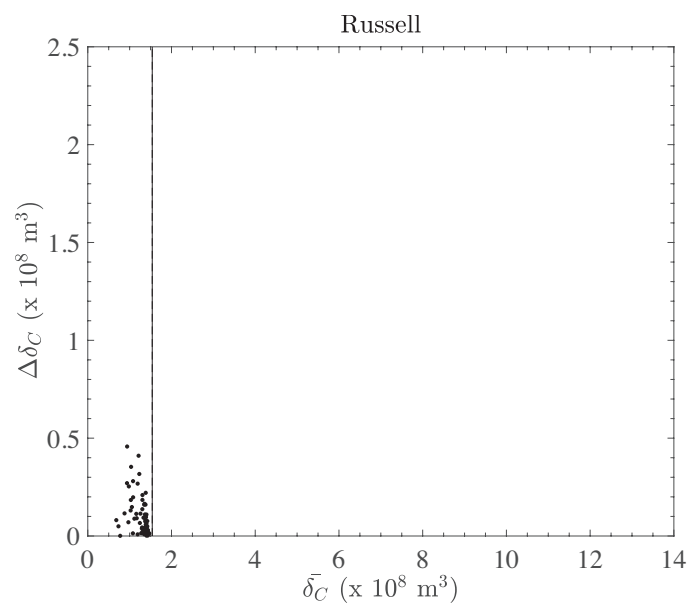

(d)

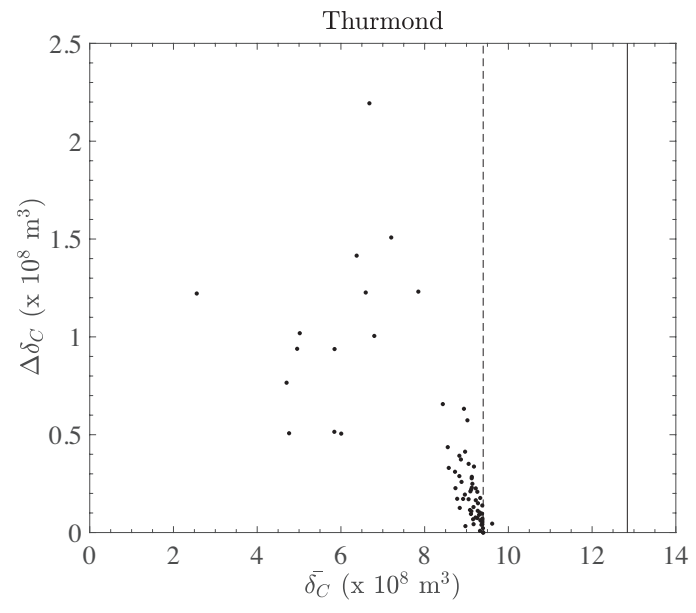

(e)

Figure 6. Historical simulated $\delta_{C}$ variation: (a) Jocassee; (b) Keowee; (c) Hartwell; (d) Russell; and (e) Thurmond. Full pool and $Z_{m i n}$ levels are represented by a solid and dashed vertical line, respectively. 

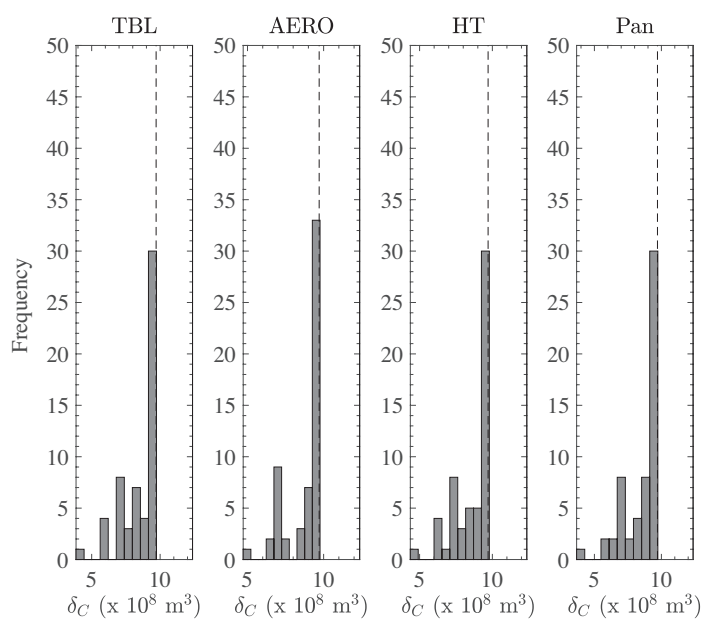

(a)
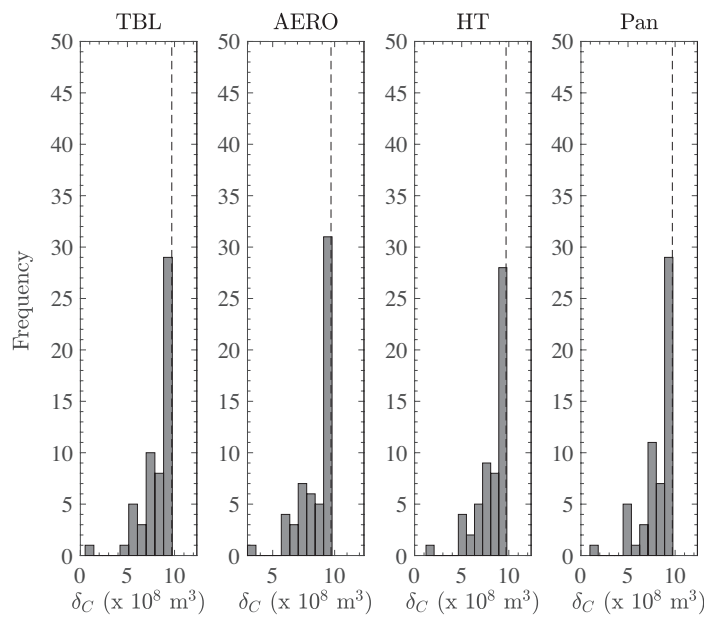

(b)

Figure 7. Lake Hartwell $\delta_{C}$ histogram: (a) historical water use; and (b) future water use. Full pool and $Z_{\text {min }}$ levels are represented by a solid and dashed vertical line, respectively.

The above interval was selected because future industry and population growth data were available only for 57 years, while the historical data were available for 70 years (i.e., the historical POR was from 1939 to 2008). Moreover, the future water-use scenario incorporated the historical UIF data set from 1952 to 2008. Sample histograms for Lake Hartwell's $\delta_{C}$ distribution are presented in Figure 7, and the summary statistics of $\delta_{C}$ are presented in Tables 3 and 4 for each reservoir. The general patterns and shifts in the $\delta_{C}$ distributions between historical and future water-use scenarios were very similar for all five reservoirs. Overall, the mean $\delta_{C}$ decreased for the future water-use scenario, while the standard deviation (StD) and coefficient of variation (CoV) increased significantly. For example, the mean $\delta_{C}$ for Lake Hartwell for the TBL model decreased from $8.58 \times 108 \mathrm{~m}^{3}$ to $8.19 \times 108 \mathrm{~m}^{3}$ from the historical to future water-use scenarios. The standard deviation (StD) and coefficient of variation $(\mathrm{CoV})$ increased from $1.35 \times 108 \mathrm{~m} 3$ and 0.16 to $1.78 \times 108 \mathrm{~m}^{3}$ and 0.22 , respectively, from the historical to future water-use scenario. Therefore, under the future wateruse scenario, uncertainty in the predicted available water increased.

\section{RESERVOIR-SPECIFIC WATER AVAILABILITY RISK}

During the development of water-resource plans and management schemes, the risk of failure is often quantified by an exceedance probability, $P_{e}$, to hydrologic events (Chin 2006) and is related to the return period, $T$, by:

$$
T=\frac{1}{P_{e}}
$$

where $T$ is the average number of years between events. Evaluating the return period of extreme events allows water-resource managers to assess the reliability of any hydrologic system. Here we use $T$ as a proxy for the sensitivity of water-availability predictions with respect to evaporation parameterizations coupled with increased water consumption. In Figure 8, the return periods are presented for each of the five major SRB reservoirs and evaporation methods. The return periods presented in Figure 8 were generated by first computing an empirical cumulative density function $(\mathrm{CDF})$ from each $\delta_{C}$ data set, as opposed to fitting probability distributions to each data set. This was done because each reservoir is heavily managed and may not be well represented by fitted probability distributions. Here, a critical event was considered to occur when $\delta_{C}$ falls halfway between the annual target minimum volume $\left(\forall_{\text {min }}\right)$ and the volume remaining at the critical intake $\left(\forall_{\text {critical }}\right)$. This critical event represents the case when $50 \%$ of the annual minimum available water is depleted. Return periods, in years, were then computed using the extreme event volumes, the empirically computed CDFs, and Equation 13.

As shown in Figure 8, the AERO method generally produced the highest return periods for all reservoirs for both the historical and the future water-use scenarios. A clear pattern among the remaining methods was not present. In all cases, predicted return periods decreased when moving from the historical to the future water-use scenarios. In some instances, the overall observed difference between historical and future return periods was greater than individual return periods. For example, the distance between Lake Thurmond's historical and future return periods for the AERO method was much larger than either of the return periods computed using the pan method.

For Lake Hartwell, Figure 8 illustrates that as water consumption increased, the return period for each evaporation method decreased. Furthermore, there was a considerable amount of uncertainty in the predicted return 
Table 3. Summary statistics of $\delta_{C}$ for historical water use.

\begin{tabular}{|c|c|c|c|}
\hline Model & Mean $\left(\times 108 \mathrm{~m}^{3}\right)$ & StD $\left(\times 108 \mathrm{~m}^{3}\right)$ & CoV \\
\hline \multicolumn{4}{|c|}{ Jocassee } \\
\hline TBL & 2.04 & 0.55 & 0.27 \\
\hline AERO & 2.12 & 0.47 & 0.22 \\
\hline HT & 2.07 & 0.51 & 0.25 \\
\hline Pan & 2.04 & 0.55 & 0.27 \\
\hline \multicolumn{4}{|c|}{ Keowee } \\
\hline TBL & 1.25 & 0.18 & 0.14 \\
\hline AERO & 1.29 & 0.15 & 0.12 \\
\hline $\mathrm{HT}$ & 1.26 & 0.16 & 0.13 \\
\hline Pan & 1.25 & 0.18 & 0.15 \\
\hline \multicolumn{4}{|c|}{ Hartwell } \\
\hline TBL & 8.58 & 1.35 & 0.16 \\
\hline AERO & 8.83 & 1.18 & 0.13 \\
\hline HT & 8.67 & 1.26 & 0.15 \\
\hline Pan & 8.64 & 1.36 & 0.16 \\
\hline \multicolumn{4}{|c|}{ Russell } \\
\hline TBL & 1.25 & 0.19 & 0.15 \\
\hline AERO & 1.25 & 0.20 & 0.16 \\
\hline HT & 1.26 & 0.19 & 0.15 \\
\hline Pan & 1.24 & 0.20 & 0.16 \\
\hline \multicolumn{4}{|c|}{ Thurmond } \\
\hline TBL & 8.21 & 1.73 & 0.21 \\
\hline AERO & 8.47 & 1.39 & 0.16 \\
\hline HT & 8.29 & 1.60 & 0.19 \\
\hline Pan & 8.30 & 1.72 & 0.21 \\
\hline
\end{tabular}

periods between the mass transfer methods and the pan method. For example, the TBL, AERO, and HT methods had approximate historical return periods of 38,53 , and 46 years, respectively. The pan method produced a historical return period of 38 years. As a result, the return periods generated from the historical water-use scenario had a total uncertainty of 15 years. However, uncertainty among the predicted return periods was only 7 years for the future water-use scenario.

\section{BASIN-WIDE WATER-AVAILABILITY RISK}

Figure 8 provides some indication of the uncertainty in the individual SRB reservoir's water-availability predictions
Table 4. Summary statistics of $\delta_{C}$ for future water use.

\begin{tabular}{|c|c|c|c|}
\hline Model & Mean $\left(\times 10^{8} \mathrm{~m}^{3}\right)$ & $\mathrm{StD}\left(\times 10^{8} \mathrm{~m}^{3}\right)$ & $\mathrm{CoV}$ \\
\hline \multicolumn{4}{|c|}{ Jocassee } \\
\hline TBL & 1.90 & 0.67 & 0.35 \\
\hline AERO & 2.03 & 0.58 & 0.29 \\
\hline HT & 1.93 & 0.64 & 0.33 \\
\hline Pan & 1.90 & 0.66 & 0.34 \\
\hline \multicolumn{4}{|c|}{ Keowee } \\
\hline TBL & 1.20 & 0.25 & 0.21 \\
\hline AERO & 1.24 & 0.22 & 0.18 \\
\hline HT & 1.21 & 0.24 & 0.20 \\
\hline Pan & 1.21 & 0.24 & 0.20 \\
\hline \multicolumn{4}{|c|}{ Hartwell } \\
\hline TBL & 8.19 & 1.78 & 0.22 \\
\hline AERO & 8.55 & 1.43 & 0.17 \\
\hline HT & 8.29 & 1.67 & 0.20 \\
\hline Pan & 8.25 & 1.75 & 0.21 \\
\hline \multicolumn{4}{|c|}{ Russell } \\
\hline TBL & 1.23 & 0.23 & 0.19 \\
\hline AERO & 1.20 & 0.28 & 0.23 \\
\hline HT & 1.22 & 0.23 & 0.19 \\
\hline Pan & 1.23 & 0.25 & 0.20 \\
\hline \multicolumn{4}{|c|}{ Thurmond } \\
\hline TBL & 7.94 & 2.05 & 0.26 \\
\hline AERO & 8.16 & 1.75 & 0.21 \\
\hline $\mathrm{HT}$ & 7.99 & 1.98 & 0.25 \\
\hline Pan & 8.02 & 2.06 & 0.26 \\
\hline
\end{tabular}

as a function of uncertainty in evaporation estimates and increased water consumption. However, the SRB reservoirs are coupled, and the effect of one reservoir output will closely affect the operation and function of downstream and upstream reservoirs, suggesting the utility of a complete basin evaluation. Due to differences in the stage-storage relationship among each of the major SRB reservoirs, a basin $\delta_{C}$ distribution would not provide a meaningful measure of total basin water availability. Therefore, the total water volume above all the reservoir critical intakes is used for this system-level analysis. The daily simulated available storage volume was computed for each evaporation model 
and water-use scenario. These values were then used to determine the SRB annual-minimum storage volume for each evaporation model and water-use scenario. Next, the ratio of the minimum available storage volume to the annual target minimum storage volume was computed for each evaporation model and water-use scenario. This ratio was given by:

$$
\forall_{\alpha}=\frac{\forall_{a}}{\forall_{t}}
$$

where $\forall \alpha$ was the annual-minimum storage volume and $\forall t$ was the annual target minimum storage volume. The ratios provided SRB water-availability distributions for the historical and future water-use scenarios. Figure 9 presents SRB histograms of $\forall \alpha$, while summary statistics of $\forall \alpha$ are presented in Tables 5 and 6 .

As shown in Table 6, the AERO, HT, and pan method all experienced a decrease of 0.03 in the mean $\forall \alpha$, while TBL's mean fell by 0.04 . Increased water consumption caused the standard deviation (StD) to increase anywhere from 0.03 to 0.05 . However, the coefficient of variation $(\mathrm{CoV})$ increased by a range of 0.04 to 0.06 . This result encapsulates the SRB uncertainty and variation in water availability with respect to not only evaporation, but also increased water usage.

Basin return periods were generated using $\forall \alpha$ for a $50 \%$ minimum basin storage volume. The return periods are presented in Figure 10. Similar to individual reservoir return periods, the figure shows that the AERO method produced the highest return period for both the historical and the future water-use scenarios, approximately 40 and 30 years, respectively. Under the historical water-use scenario, the HT method fell within approximately 4 years of the AERO method, while the TBL and the pan method predicted

Table 5. Summary statistics of $\forall \alpha$ for historical water use.

\begin{tabular}{cccc}
\hline Model & Mean & StD & CoV \\
\hline TBL & 0.89 & 0.16 & 0.18 \\
AERO & 0.91 & 0.13 & 0.14 \\
HT & 0.90 & 0.14 & 0.16 \\
Pan & 0.90 & 0.16 & 0.17 \\
\hline
\end{tabular}

Table 6. Summary statistics of $\forall \alpha$ for future water use.

\begin{tabular}{cccc}
\hline Model & Mean & StD & CoV \\
\hline TBL & 0.85 & 0.19 & 0.23 \\
AERO & 0.88 & 0.16 & 0.18 \\
HT & 0.86 & 0.19 & 0.22 \\
Pan & 0.86 & 0.19 & 0.23 \\
\hline
\end{tabular}

a return period of approximately 30 years. Uncertainty in the predicted historical return periods among the three mass transfer methods and the pan method was relatively small. However, increased water consumption within the SRB greatly affected this result. During the future water-use scenario, the TBL and pan methods both predicted return periods of approximately 9 years. However, the AERO and the HT methods predicted future return periods of 31 and 20 years, respectively. The range of predicted return periods for the future water-use scenario created a total uncertainty of 22 years, as opposed to 7 years for the historical water-use scenario, a $214 \%$ increase.

\section{CONCLUSIONS}

Uncertainty in predicted water availability for reservoirs in the Savannah River Basin was generally only observed during drought conditions. Results presented herein show that as reservoir levels fall from full-pool elevation, uncertainty in predicted available water increases due to uncertainty in reservoir evaporation estimates. During drought periods, uncertainty in evaporation estimates begin to impact predicted water availability much more due to lower reservoir levels. Uncertainty in water-availability predictions were magnified when water consumption increased due to projected industry and population growth.

Basin return periods for exceedance probabilities under severe hydrologic stress were used as an additional measure of uncertainty in water-availability predictions on a basin scale. The observed uncertainty in the predicted return periods was approximately 7 years for the historical wateruse scenario and 22 years for the future water-use scenario.

The observed uncertainty in water-availability predictions is a direct result of the uncertainty in evaporation estimates. Under normal flow conditions, the uncertainty is small due to an abundance of water. As a result, any one of the four evaporation methods used in this paper performs well in evaluating water availability. However, under drought conditions, the uncertainty in evaporation estimates caused significant uncertainty in the total available water. Increased water consumption from industry and population growth intensifies this effect. The uncertainty in water availability was estimated to increase substantially with future increases in water consumption. Herein, constant daily projected wateruse data were incorporated to evaluate such uncertainties that may be typical for engineering studies. Such assumptions should be further evaluated and tested with consideration given to seasonal variability in future water consumption, changes in rainfall patterns, and other climate changeinduced stresses. 
Phillips, Kaye, Saylor

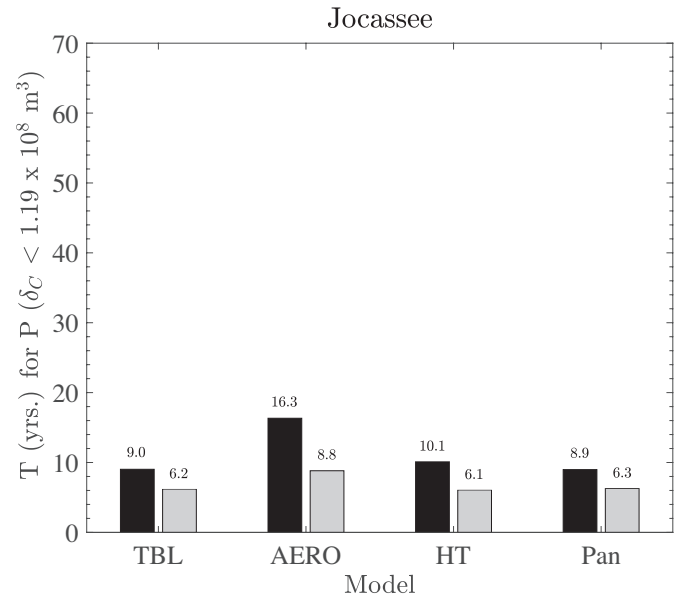

(a)

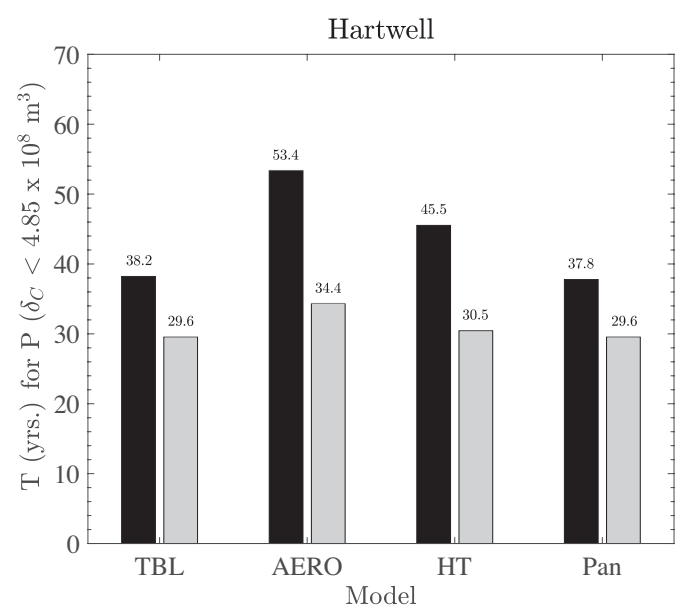

(c)

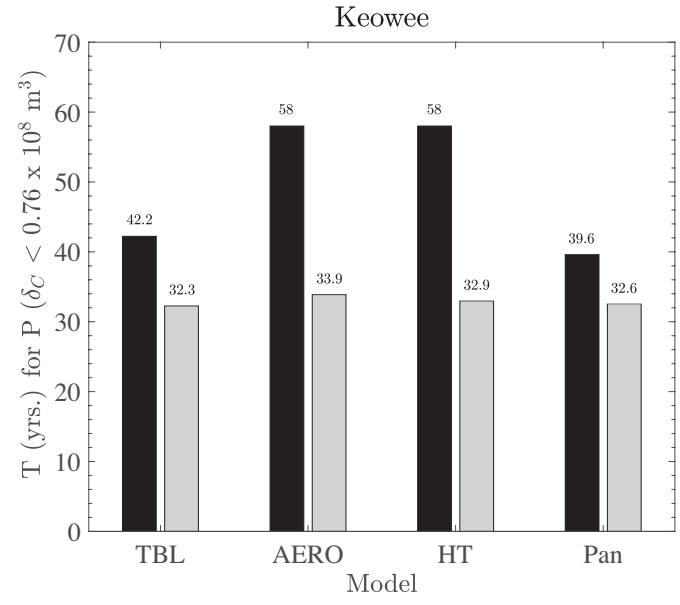

(b)

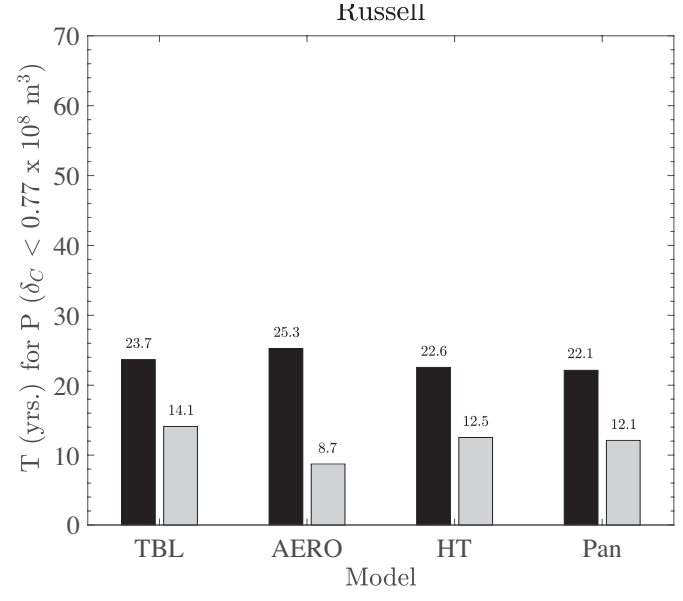

(d)

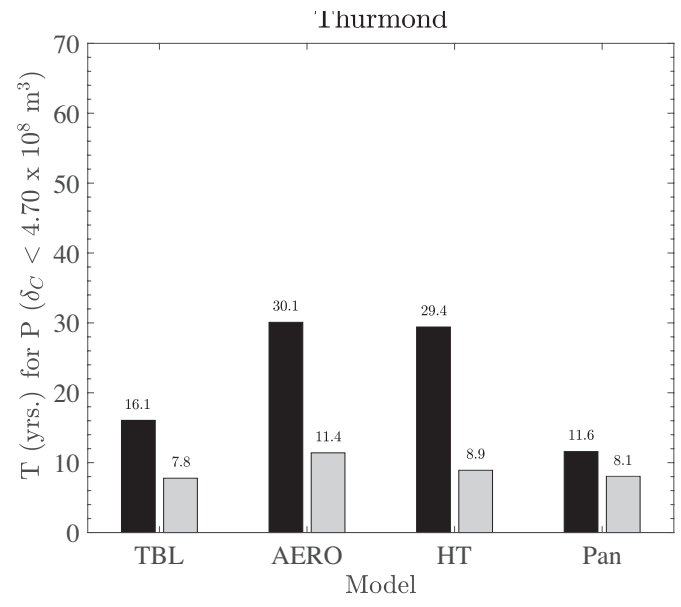

(e)

Figure 8. Reservoir return periods for falling within $50 \%$ of available $\delta_{C}$ under historical (black) and future (grey) water use scenarios: (a) Jocassee; (b) Keowee; (c) Hartwell; (d) Russell; and (e) Thurmond. 


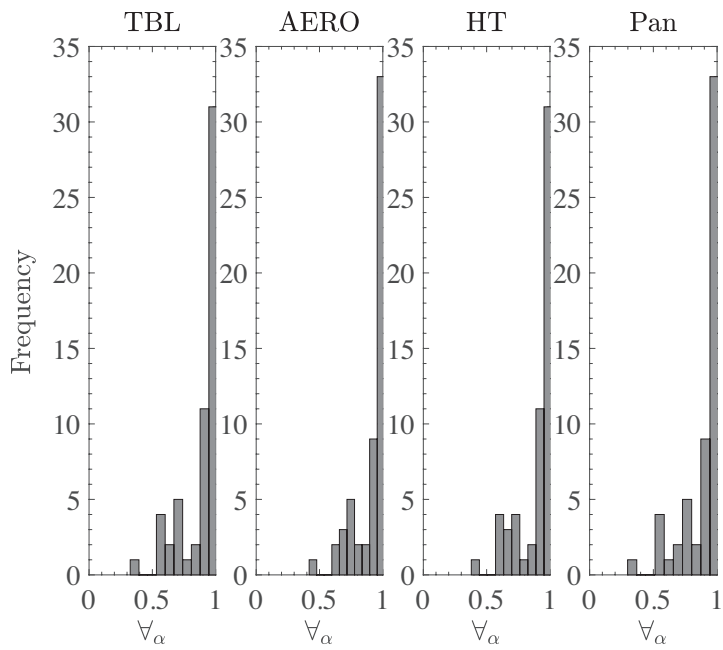

(a)

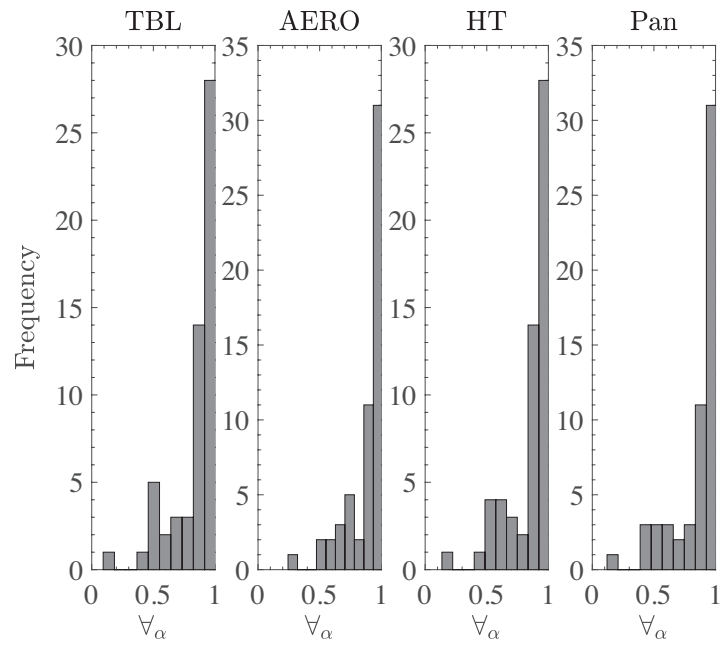

(b)

Figure 9. SRB histogram of $\forall \alpha$ : (a) historical water use; and (b) future water use.

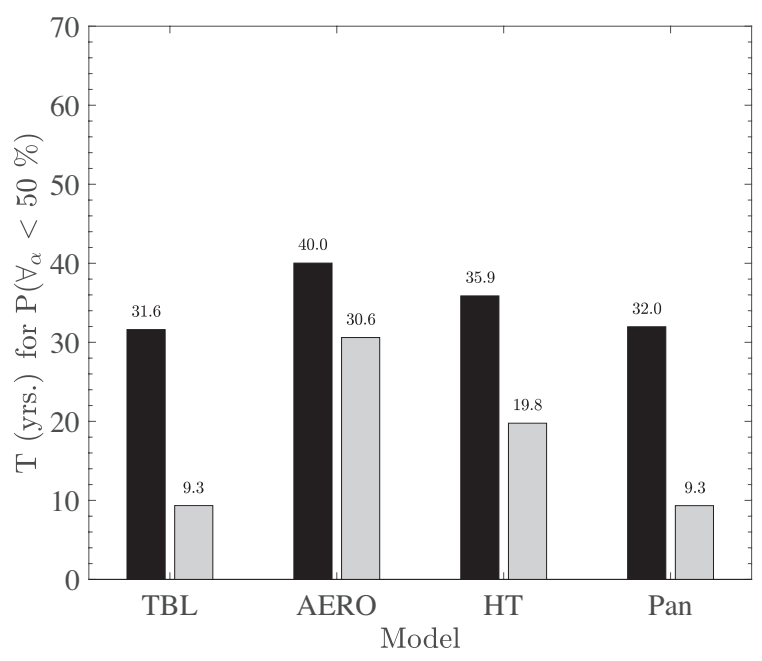

Figure 10. SRB return periods for falling within $50 \%$ of the annualminimum storage volume for historical (black) and future (grey) wateruse scenarios.

\section{ACKNOWLEDGMENTS}

The authors thank the United States of Army Corps of Engineers (USACE) Savannah District and the Georgia Environmental Protection Division (GA EPD) for their assistance in providing modeling and support files, which were fundamental to this research. This work was funded by the South Carolina Water Resources Center of Clemson University via the United States Geological Survey (USGS) whose support is greatly acknowledged. This material is partially based on work supported by the National Science Foundation under Grant No. 1011478. Any opinions, findings, and conclusions or recommendations expressed in the material are those of the authors and do not necessarily reflect the views of the National Science Foundation.

\section{REFERENCES}

ARCADIS U.S., Inc. 2010. Unimpaired Flow Data Report. Atlanta: ARCADIS U.S., Inc.

Barber NL, Stamey, T C. 2000. Droughts in Georgia. Atlanta: US Department of the Interior, US Geological Survey.

Brutsaert WH. 1982. Evaporation into the atmosphere: theory, history, and applications. D. Reidel Publishing Company.

Chin DA. 2006. Water-resources engineering. Hoboken, NJ: Pearson.

Douglas J. 2002. South Carolina droughts and floods, 1893-2002. Washington, DC: US Geological Survey.

Farnsworth RK, Thompson, ES. 1982. Mean monthly, seasonal, and annual pan evaporation for the United States. NOAA Technical Report NWS 34. Washington, DC: Office of Hydrology, National Weather Service.

GA EPD. 2000. Savannah River Basin watershed protection plan. Atlanta: Georgia Environmental Protection Division.

Gleick PH. 1987. The development and testing of a water balance model for climate impact assessment: modeling the Sacramento Basin. Water Resources Research. 23(6):1049-1061.

Greenville Water Systems. 2012. Greenville Water Annual Report. Greenville, SC: Greenville Water Systems.

Gupta RS. 2001. Hydrology and Hydraulic Systems. Long Grove, IL: Waveland Press.

Ham, J. M. 1999. Measuring evaporation and seepage losses from lagoons used to contain animal waste. Transactions of the ASAE. 42(5):1303-1312.

HDR Engineering, Inc., of the Carolinas. 2013. Water supply study-final report: Keowee-Toxaway HydroelectricRelicensing Project. Columbia, SC: HDR Engineering. Julien Y, Sobrino JA, Verhoef W. 2006. Changes in land surface temperatures and NDVI values over Europe 


\section{Phillips, Kaye, Saylor}

between 1982 and 1999. Remote Sensing of Environment. 103(1):43-55.

Lettenmaier DP, Gan TY. 1990. Hydrologic sensitivities of the Sacramento-San Joaquin River Basin, California, to global warming. Water Resources Research. 26(1):69-86.

Nadolski VL. 1998. Automated Surface Observing System (ASOS) User's Guide. Washington, DC: National Oceanic and Atmospheric Administration.

Phillips R, Saylor JR., Kaye NB, Gibert JM. 2016. A multi-lake study of seasonal variation in lake surface evaporation using MODIS satellite derived surface temperature. Limnology. 17(3):273-289.

Rosenberry DO, Winter TC, Buso DC, Likens GE.2007. Comparison of 15 evaporation methods applied to a small mountain lake in the northeastern USA. J. Hydrology. 340:149-166.

Sartori E. 2000. A critical review on equations employed for the calculation of the evaporation rate from free water surfaces. Journal of Solar Energy. 68:77-89.

Tarboton DG. 1995. Hydrologic scenarios for severe sustained drought in the southwestern United States. Journal of the American Water Resources Association. 31(5):803-813.
United States Army Corps of Engineers (USACE). 2006. Draft environmental assessment and finding of no significant impact. Drought contingency plan update Savannah River Basin. Washington, DC: USACE.

United States Army Corps of Engineers (USACE). 2012. Savannah River Basin drought management plan. Washington, DC: USACE.

US-EPA, Region 4, SESD. 1999. Savannah River Basin REMAP: a demonstration of the usefulness of probability sampling for the purpose of estimating ecological condition in state monitoring programs. Washington, DC: US-EPA.

Xu Y, Shen Y, Wu Z. 2013. Spatial and temporal variations of land surface temperature over the Tibetan Plateau based on harmonic analysis. Mountain Research and Development. 33(1):85-94.

\section{APPENDIX A}

Table A.1. Summary of data, use, and source for the major inputs required for evaporation and water-availability modeling.

\begin{tabular}{|c|c|c|}
\hline Data & Use & Source \\
\hline$T_{a}, \varphi$, and $\bar{U}_{r}$ & Mass Transfer Evaporation & Automated Surface Observation System (ASOS) \\
\hline$T_{s}$ & Mass Transfer Evaporation & $\begin{array}{l}\text { Moderate-Resolution Imaging Spectroradiometer } \\
\text { (MODIS_TERRA/AQUA) }\end{array}$ \\
\hline$F W S_{\text {grid }}$ and $E_{\text {Pan }}$ & Pan Evaporation & National Weather Service (NWS) \\
\hline $\begin{array}{c}\text { UIF, LIF, NETEVAP }, \text { NETWU, } \\
P, A, \text { and } R O C\end{array}$ & Unimpaired Flow & Georgia Environmental Protection Division (GA EPD) \\
\hline Future $N E T W U$ & Unimpaired Flow & HDR 2013 \\
\hline 2006-DCP & Basin Water-Availability Modeling & $\begin{array}{l}\text { United States Army Corps of Engineers (USACE) } \\
\text { Savannah District }\end{array}$ \\
\hline
\end{tabular}

